\title{
III. Zum mikroskopischen Nachweis von Cholerabacillen in Dejectionen ${ }^{1}$ ). \\ Von Professor Dr. Max Schottelius.
}

In einer vor kurzem erschienenen Abhandlung „Ueber den augenblicklichen Stand der bacteriologischen Choleradiagnose" 2) beschreibt R. Koch ein von mir im Jahre 1885 veröffentlichtes Verfahren zum Nachweis von Cholerabacillen in Dejectionen ${ }^{3}$ ) und weist der betreffenden Methode eine so hervorragende Bedeutung für die bacteriologische Diagnose der Cholera zu, dass mancher, der nicht sehr genall mit den einschlägigen Untersuchungsverhältnissen vertraut ist, dazu verführt werden könnte, von dem Ausfall dieser Art der bacteriologischen Untersuchung sein Urtheil vom Vorhandensein oder Nichtvorhandensein von Cholera abhängig zu machen.

Um einer Ueberschätzung der Tragweite der von mir eingeführten Untersuchungsmethode bei einer vielleicht schon in nächster Zeit uns drohenden Choleragefahr vorzubeugen, sehe ich mich nach dem Erscheinen der Koch'schen Arbeit schon jetzt veranlasst, einige weitere Angaben über die im Laufe der letzten Jahre eingetretenen Verbesserungen meiner Methode zu machen, Verbesserungen, welche theils auf Grund theoretischer, wissenschaftlicher Arbeiten im Laboratorium, anderntheils während der letzten Choleraepidemie im Eppendorfer Krankenhause zu Hamburg auf Grund praktischer Erfahrungen aufgesucht und geprüft wurden.

Es würde mir lieb gewesen sein, wenn ich mit dieser Veröffentlichung noch einige Zeit hätte zurückhalten können, denn auch heute erscheint mir die Methode noch nicht nach allen Richtungen hin genügend durchgearbeitet zu sein, um von Jedermann in praxi nutzbringend gehandhabt werden zul können. Inzwischen wird durch die Koch'sche Abhandlung der klare Einblick in die wissenschaftliche Bedeutung und in die historische Entwickelung der Frage des Nachweises von Cholerabacillen in Dejectionen derart getrübt, dass ich es für meine Pflicht halte, schon jetzt in dieser Angelegenheit das Wort zu ergreifen.

Der Bericht, in welchem Koch zuerst auf das Vorhandensein von kommaförmigen specifischen Bacillen in den Dejectionen Cholerakranker hinweist ${ }^{4}$, datirt vom 2. Februar 1884. Zum Nachweise dieser in Dejectionen befindlichen Kommabacillen wurde neben der direkten mikroskopischen Untersuchung bekanntlich das Koch'sche Gelatineplattenverfahren empfohlen und in der nächsten Zeit ausschliesslich angewandt.

Im Herbst desselben Jahres sah ich mich während meiner zum Zwecke von Cholerastudien angestellten Reise nach Oberitalien unter dem Zwange äusserer Verhältnisse genöthigt, ein einfacheres Verfahren zu ersinnen, um die Cholerabacillen in Dejectionen rasch nachzuweisen. Die Handhabe zur Entdeckung des neuen Verfahrens gab mir Pasteur's vielfach hervorgehobene Behauptung, dass feste Nährböden im ganzen ein Wachsthumshinderniss darstellen, und dass ein flüssiger Nährboden dem raschen Wachsthum von Spaltpilzen im grossen und ganzen bessere Bedingungen bietet. Des weiteren war durch die Koch'schen Untersuchungen die lebhafte Eigenbewegung der Cholerabacillen und ihr intensives Bedürfniss nach freiem athmosphärischem Sauerstoff bekannt. Ebenfalls war bereits festgestellt, dass das Optimum für das Wachsthum von Cholerabacillen etwa in der Höhe der Körpertemperatur liegt. Durch Combination dieser Factoren ergab sich dann das von mir in der Deutschen medicinischen Wochenschrift No. 14 vom 2. April 1885 veröffentlichte Verfahren, welches inzwischen vielfach nachgeprüft und praktisch brauchbar befunden ist ${ }^{5}$ ).

Im Laufe der folgenden Jahre wurde namentlich von Gruber ${ }^{6}$ ) eine Modification meines Verfahrens als Verbesserung empfohlen, und es findet sich seitdem die betreffende Untersuchungsmethode in der Litteratur vielfach unter dem Namen der SchotteliusGruber'schen oder Gruber-Schottelius'schen Methode angeführt.

Wieso R. Koch auf p. 323 seiner oben erwähnten Abhandlung "Ueber den augenblicklichen Stand der Choleradiagnose" zu der Behauptung kommen kann, dass es "sich nicht immer mit Bestimmtheit sagen lässt. wem wir die Verbesserung des Verfahrens zur Abkürzung desselben zu verdanken haben “ _- und dass ,jene Verbesserungen bisher entweder gar nicht oder ungenügend bekannt geworden sind" - das ist mir sowie vielen anderen - unverständlich.

1) Nach einem Vortrage, gehalten bei Gelegenheit des XIV. Oberrheinischen Aerztetages in Freiburg i. B.

$\left.{ }^{2}\right)$ Zeitschrift für Hygiene XIV 2, p. $319 \mathrm{ff}$.

3) Deutsche medicin. Wochenschr. 1885 No. 14, p. 213.

4) Arbeiten aus dem Kaiserl. Gesundheitsamt III 1887, Anlage 2, p. 23.

5) di Vestea, Sulla bonta di metodo Schottelius etc. Giornale internazionale del Scienze medic. 1887.

$\left.{ }^{6}\right)$ Wiener medicin. Wochenschrift 1887 No. 7 u. 8 
Was die Gruber'sche Verbesserung meiner Methode betrifft, welche den Zweck hatte, durch die Stoffwechselproducte der Cholerabacillen das gleichzeitige Wachsthum anderer Bacterien zurückzudrängen, und welche zu den Culturversuchen Proberöhrchen beuutzte, so möchte ich nicht ohne weiteres diese Modification als eine Verbesserung zugeben, namentlich haben mir grosse und weite Gefässe in einem grösseren Procentsatz ceteris paribus positive Erfolge geliefert, als Proberöhrchen selbst bei Schräglage derselben. An Stelle der choleradurchwachsenen Peptonbouillon kann ebenfalls nach meinen Erfahrungen ohıe Schädigung der Resultate jede andere, die nöthigen Nälırwerthe enthaltende und bis zu $1 \%$ durch Soda alkalisch gemachte Bouillon treten. Inzwischen scheint auch mir Gruber's Gedanke, die Stoffwechselproducte der Cholerabacillen als Wachsthumshemmnisse für andere Bacterien zu verwerthen, ein äusserst glïcklicher zu sein, und wird gewiss in einer oder anderer Form demnächst seine praktische Verwerthung finden.

Weiter machte die Untersuchung verdächtiger Dejectionen auf den Nachweis von Cholerabacillen einen wesentlichen Fortschritt durch die zuerst von M. Dahmen ${ }^{1}$ ) gegebene Mittheilung, dass „eine Gelatine mit $1 \%$ Soda“ die Lebensfähigkeit von Kommabacillen am intensivsten entfache.

Die Richtigkeit dieser Angabe kann ich auf Grund einer grossen Reihe mit künstlichen Culturen angestellter und praktischer (mit den Dejectionen von Cholerakranken direkt vorgenommener) Versuche bestätigen.

Ich selbst hatte den Grad der Alkalescenz niemals in den Bereich meiner Experimente gezogen, sondern nur nach verschiedenen anderen, weiter unten zu beschreibenden Richtungen hin die äusseren Lebensbedingungen der Kommabacillen variirt, und war in hohem Grade erstaunt und freudig iiberrascht, in dieser von M. Dahmen zuerst angegebenen Modificirung des Nährbodens einen so mächtigen Factor für die rasche Entwickelung der Kommabacillen $\mathrm{zu}$ finden.

In einem späteren Stadium der Untersuchung, d. h. wenn es zul reichlicher Entwickelung von Cholerabacillen bereits gekommen ist und diese demnach durch die mikroskopische Untersuchung nachgewiesen werden können, kann die sogenannte Cholerarothreaction zur weiteren Sicherstellung verwandt werden. Dieselbe wurde zuerst von 0 . Bujwid beschrieben im zweiten Bande der Zeitschrift für Hygiene 1887, p. 52, und nicht, wie Koch ${ }^{2}$ ) meint, von Dr. Edward K. Dunham, welcher zwar in demselben Jahrgang der Zeitschrift für Hygiene, aber erst zu einer späteren Zeit seine Abhandlung "Zur chemischen Reaction der Cholerabacterien“ niederlegte. Dunham selbst bezieht sich eingangs seiner Arbeit auf die Angaben von Bujwid, und es kann sonach kein Zweifel bestehen, wem das Prioritätsrecht der Entdeckung dieser Reaction zul wahren ist.

Was die von Koch citirte Arbeit von Hesse betrifft, an welcher "so iiberzeugend das sehr hohe Sauerstoffbedürfniss der Cholerabacterien" nachuewiesen wurde, so hat schon Bonhoff ${ }^{3}$ ) darauf aufmerksam gemacht, dass über ein hohes Sauerstoffbedürfniss der Cholerabacterien sich in dieser Arbeit überhaupt keine Angabe findet; es muss da also wohl irgend eine Verwechselung von Seiten Koch's vorliegen.

Wenn ich mir gestattet habe, einen kurzen Rückblick auf die gesehichtliche Entwickelung der Methoden des Nachweises von Kommabacillen in Dejectionen zu geben, so geschal es, $1 \mathrm{~m} \mathrm{zu}$ zeigen, dass die ursprüngliche Methode der Cultivirung in „alkalischer Fleischbrühe" oder "zehnfach verdünnter Fleischpeptongelatine"4) noch heute im Princip zu Recht besteht, und dass die litterarische Beurtheilung dieser Frage an der Hand unserer allgemein zugänglichen Fachzeitschriften jedem leicht ermöglicht ist.

Dass mir selbst daran gelegen sein musste, eine weitere Vervollkommnung meiner Methode, deren Mängel mir am wenigsten unklar waren, anzustreben, ist wohl verständlich, und so war mir namentlich die von Dahmen gemachte Angabe über das Optimum des Alkalescenz der Nährböden für Cholerabacillen von hohem Werthe. In der That liess eine Reihe von Fällen, in denen es sich um die Isolirung von Cholerabacillen aus Bacteriengemjschen handelte, positive Untersuchungsresultate erzielen, welche bei der geringeren Alkalescenz der früher benutzten Nährböden ausgeblieben waren. Aber auch noch iiber eine andere Modification meiner Methode, welche seit längerer Zeit sich mir bewährt hat und wohl noch einer weiteren Vervollkommnung fähig ist, möchte ich bei dieser Gelegenheit berichten.

Bereits seit einigen Jahren wird am hygienischen Institut zu

1) Centralbl. f. Bacteriol. XII. No. 18, p. 620 .

3) l. c. p. 326

3) Berl. klin. Wochenschrift 1893 No 24.

$4)$ Deutsche med. Wochenschrift 1885 No. 14.
Freiburg mit Infusen von menschlichem und thierischem Dünndarminhalt als Nährboden für Bacterien gearbeitet, und es hat sich gezeigt, dass derartiges Dünndarminfus für viele Zwecke einen sehr geeigneten Nährboden darstellt.

Bekanntlich hat bereits Leubuscher ${ }^{1}$ ) über den Einfluss von Verdauungssecreten auf Bacterien gearbeitet und im allgemeinen gefunden, dass in den keimfrei entnommenen Darmsäften namentlich Cholera- und Typhusbacillen sich im allgemeinen gut entwickeln, dass die Fermente verdallender Natur keinen Einfluss auf die lebenden Organismen haben, und dass nur den freien Gallensäuren eine antimykotische Kraft zukommt.

Bei den von mir in Anwendung gebrachten Dünndarminhaltinfusen wünschte ich den verschiedenen hierhergehörigen Spaltpilzen einen ihren für den Menschen in Betracht kommenden Lebensäusserungen möglichst gut angepassten Nährboden zu verschaffen resp. die gleichen Bedingungen zu setzen, unter denen sie in der für den Menschen praktisch bedeutungsvollen Form und Menge auftreten.

Da ich für meine Zwecke eines sterilen Nährbodens nicht bedarf, indem es sich überhaupt nur um das Herauswachsen einer Art aus einem Bacteriengemisch handelt, so konnte die Methode der Gewinnung des Rohmaterials sich sehr einfach gestalten: Am besten eignen sich ganz frische menschliche Leichen von Personen, welche nachweislich nicht an Krankheiten des Tractus intestinalis zur Behandlung kamen. Diesen wird ein ungefähr $1 \mathrm{~m}$ langes Stück des Jejunum und oberen Ileum entnommen, und der breiige Inhalt desselben durch Ausstreichen in ein geeignetes Gefäss entleert. Gewöhnlich erhält man ungefähr $200 \mathrm{cem}$ Darminhalt.

Diese Portion wird durch Wasserzusatz auf einen Liter gebracht, mit Soda soweit alkalisirt, dass eine $1 \%$ ige Lösung entsteht, filtrirt und womöglich sofort benutzt.

Die filtrirte Flüssigkeit ist meistens weissgrau, milchig getrübt und enthält spärliche, mikroskopisch nachweisbare Darmbacterien.

Dünndarminfuse, welche stark gallig gefärbt sind und klar filtriren, eignen sich weniger gut für unsere Zwecke als solche mit den erwähnten Eigenschaften.

Die Haltbarkeit dieser Darminfusnährböden ist natürlich eine zeitlich sehr begrenzte. Inzwischen kann man durch Anwendung niederer Temperatur die Infuse ganz gut 10-14 Tage in brauchbarem Zustande conserviren.

Ich hatte das Darminfus ursprünglich für Versuche mit Typhusbacillen und dem Bacterium coli commune hergestellt und zuerst von Jenniczewski in einer demnächst erscheinenden Abhandlung über einen Fall von Uebertragung des Thyphus auf den Fötus anwenden lassen, und bin erst im vorigen Sommer kurz vor Ausbruch der Hamburger Choleraepidemie dazu übergegangen, Darminfus auch als Nährboden für Cholerabacillen, speciell zur Vervollkommnung meiner Methode zum Nachweis von Cholerabacillen in Dejectionen zu verwerthen.

Dabei hat sich gezeigt, dass solches Darminfus in ganz hervorragender Weise das Wachsthum der Cholerabacillen unterstützt, so dass selbst in Fällen, in denen die alte - neuerdings von Koch so warm empfohlene -- Methode nicht ausreicht, noch positive Resultate erzielt werden. Die Cholerabacillen ",reichern sich“ (um mich dieses von $\mathrm{Koch}$ neu eingefïhrten Wortes $\mathrm{zu}$ bedienen) schneller an, als auf irgend einem anderen Nährboden, und der Ausdruck der "Anreicherung" ist auch insofern ein modificirter, als gegenüber der Peptoncultur schon früher charakteristische Spirillen auftreten, welche in Bündel mit einander verflochten ein höchst auffallendes mikroskopisches Bild darbieten.

An Stelle des menschlichen Dünndarminfuses lässt sich mit ähnlich gutem Erfolg auch Dünndarminfus frisch geschlachteter Schweine verwenden; es bietet sich dadurch die Möglichkeit, überall diesen Nährboden zum Nachweis von Cholerabacillen in Dejectionen in Anwendung zu bringen.

Bei allen Vorzügen aber, welche die alte Methode und mehr noch die neue vor der alten hat, muss vor einer Ueberschätzung derselben gewarnt und dringend darauf hingewiesen werden, dass nur ein gewisser Procentsatz der zur praktischen Beurtheilung.kommenden Fälle positiv reagirt, dass aber in einem anderen gewissen Procentsatz entweder gar nicht oder erst nach einigen (2-3) Tagen Cholerabacillen an der Oberfläche des Nährbodens auftreten. Mit anderen Worten: diese Methode hat mit vielen anderen Untersuchungsmethoden das gemeinsam, dass sie nur eine relative, nicht aber eine absolute Gewähr bietet.

Vielleicht lassen sich noch weitere Verbesserungen ausfindig machen oder andere einfache Wege zur Sicherung der Choleradiagnose ersinnen, vorläufig muss ich mich aber der Ausicht derjenigen anschliessen, welche der Meinung sind, dass unsere

1) Zeitschrift fïr klin. Medicin 1890, XVII, Heft V. 
heutigen Mittel durchaus nicht in allen Fällen nach Ablauf der ersten 24 Stunden durch die bacteriologische Untersuchung die Choleradiagnose sichern.

Immerhin dürfte das beschriebene Verfahren einen brauchbaren und in den meisten Fällen zum Ziel fïhrenden Weg darstellen, rasch die Cholerabacillen in verdächtigen Dejectionen nachzu weisen; um so mehr, als es ja gegenwärtig doch eine grosse Reihe tüchtig ausgebildeter Aerzte giebt, welche nicht nur init der mikroskopischen Technik, sondern auch mit den praktisch wichtigen bacteriologischen Untersuchungsmethoden erfolgreich $\mathrm{zu}$ arbeiten wissen.

Schliesslich möchte ich noch auf einen Punkt aufinerksam machen, welcher zu falschen Schlussfolgerungen führen könnte:

Es werden vielfach, und zwar mit voller wissenschaftlicher Berechtigung, zur Förderung der in Rede stehenden Fragen künstlich gezüchtete Cholerabacillenculturen angewandt, und man ist leicht geneigt, die sich ergebenden Resultate wenigstens mittelbar auf die Praxis zu übertragen. Demgegenüber muss hervorgehobeu werden, dass die Versuche mit wirklichen, direkt dem Kranken entnommenen frischen Choleradejectionen vielfach anders verlaufen, als man nach den angedeuteten Laboratoriumsversuchen erwartel sollte.

Man hat jedenfalls mehr Chancen, aus einem künstlich hergestellten Bacteriengemisch (beispielsweise aus einfach diarrhoischem Stuhlgang, welchem man eine Bouilloncultur von Cholerabacillen zugesetzt hat) die Kommabacillen herauszucultiviren, als es in praxi mit einem wirklichen Cholerastuhlgang der Fall ist. Dabei muss man überdies noch berücksichtigen, dass es sich bei den zur ersten Diagnosestellung eingesandten oder sonst zur Untersuchung kommenden Dejectionen nicht einmal immer um typisch ausgesprochene Cholerafälle handelt, und dass diese noch nicht ganz typischen Fälle solche sind, welche für die einzuschlagenden Vorbeugungsmaassregeln die grösste Bedeutung haben.

Im Eppendorfer Krankenhause, woselbst ich durch die freundliche Fuirsorge des Herrn Direktor Rumpf und durch die liebenswürdige Unterstützung des Herrn Collegen E. Fraenkel in der Lage war, eine Reihe von Choleradejectionen in obigem Sinne zu untersuchen, ist es mir mehrfach vorgekommen, dass unter ganz gleichzeitig angesetzten Culturschalen, welche mit der Dejection eines und desselben typischen Cholerafalles beschickt waren, einige positiv, andre negativ reagirten, $d$. l. dass der mikroskopische Nachweis von Kommabacillen an einigen Schalen geführt werden konnte, an anderen dagegen ausblieb.

In praktisch wichtigen Fällen ist es daher dringend zu rathen, nicht nur eine, sondern eine grössere Reihe von Culturschalen anzusetzen. 